\title{
Exploration on Construction of Teaching Quality Evaluation Indexes in Higher Vocational Colleges
}

\author{
Jing Lu \\ Department of Information Engineering, Weihai Vocational College, Weihai Shandong, 264210, \\ China
}

Keywords: Higher vocational college, Teaching quality, Evaluation index, Construction

\begin{abstract}
Higher vocational colleges can standardize college behaviors, train innovative talents, improve the overall quality of teaching team, implement all-round quality-oriented education and enhance the quality of students cultivated by higher vocational colleges through constructing rational evaluation system. In current stage, most colleges establish higher vocational college evaluation system according to traditional evaluation method, which cannot completely comply with the demand of era development. Thus, scientific, modern and rational teaching quality evaluation system for higher vocational colleges should be established. This paper mainly analyzes basic connotation of teaching evaluation system and the problems in construction of teaching quality evaluation system, and proposes rational teaching evaluation system on this basis.
\end{abstract}

\section{Introduction}

Currently, continuous development of higher vocational college education brings more challenges and opportunities. To gain certain advantage in fierce competitions, higher vocational colleges must guarantee teaching quality which is also an effective way to boost talent training quality of higher vocational colleges. Corresponding intrinsic property exists in actual teaching activity of higher vocational colleges. To guarantee teaching quality of higher vocational colleges, teaching quality evaluation indexes not just include teaching evaluation, but also contain practical teaching, specialty setting, course setting and social reputation etc. Talent training objective of higher vocational colleges is to train high-skilled talents needed by all walks of life. Hence, teaching quality evaluation system of higher vocational colleges should not merely start from external evaluation. Besides, internal evaluation system of higher vocational colleges should be established and improved.

\section{Connotation of teaching quality of higher vocational colleges}

The basic purpose of higher vocational colleges is to train service-oriented and employment-oriented talents. In practice, higher vocational college education is an education mode which meets social demand and students' requirements. Many factors will influence teaching quality, where student's learning and teachers' work are the most important factors. In other words, it is necessary to evaluate student's learning and teachers' teaching during constructing teaching evaluation system. Compared with general education method, higher vocational education is different, which will be influenced by many factors. We can say that the ultimate goal of teaching quality of higher vocational college is to meet the talents satisfying development demand of enterprises and industries, and to construct qualified teaching quality evaluation system. Therefore, it is necessary to analyze factors in various aspects during constructing teaching quality evaluation system, keep improving talent training force and guarantee to offer basis for social development.

\section{Current situation of teaching quality evaluation of higher vocational colleges}

The development and application of teaching quality evaluation system in Chinese higher vocational colleges are still in the development stage, and certain disadvantages and defects will occur in implementation of teaching quality evaluation system. In current stage, there are mainly two teaching quality evaluation forms in higher vocational colleges. The first one is national education 
departments assess and inspect actual teaching work of higher vocational colleges. Generally, such method is called external evaluation system, i.e. improve teaching quality evaluation indexes of higher vocational colleges as far as possible according to external force. Basic feature of external evaluation is conclusive evaluation of teaching static work. The second one is internal evaluation and teaching inspection of higher vocational colleges. The fundamental objective is to continuously improve the overall level of teaching quality. This evaluation form belongs to internal evaluation. Most colleges pay attention to coping with external evaluation of relevant education departments during constructing evaluation system, and cannot practically implement internal evaluation of higher vocational colleges. Thus, the fundamental function of internal evaluation cannot be exerted. Next, this paper mainly analyzes the problems in the process where several higher vocational colleges construct teaching quality evaluation mechanism.

\section{Non-comprehensive teaching quality evaluation system}

The majority of higher vocational colleges will refer to teaching quality evaluation modes of different colleges during constructing teaching quality evaluation system. They attach importance to classroom theory teaching and neglect practical teaching link; they attach importance to teachers' teaching theory level and neglect practical operation ability and professional skills; they attach importance to teaching order monitoring and neglect internal teaching effect evaluation and connotation; they attach importance to on-campus evaluation and neglect social evaluation of enterprises and employers; they attach importance to teachers' teaching and neglect students' learning etc. Such talent evaluation mode lacks the connection with international vocational education, has defects in training "dual-qualification" teachers, promoting educational informationization level, college-enterprise cooperation and innovative talent training and restricts the development of teaching quality of higher vocational colleges.

\section{Unsound teaching quality evaluation mechanism}

In current stage, teaching quality evaluation system of most higher vocational colleges cannot completely ensure the expenditure and personnel. There is no institution which specializes in independently implementing teaching quality evaluation system. Teaching quality evaluation system department is also the teaching management department. This is adverse to rationally and accurately mastering teaching quality of higher vocational colleges, and fully showing authority and fairness of teaching quality evaluation system.

\section{Backward teaching quality evaluation means}

As higher vocational colleges continuously expand the student enrollment, and the number of teachers and students rises sharply, traditional table filling, questionnaire survey and card painting cannot completely comply with actual development demand of higher vocational colleges, which increases the difficulty in constructing evaluation system of higher vocational colleges.

\section{Failure to deeply cognize teaching quality evaluation}

The education of higher vocational colleges has particularity. The main training direction and objective are employment-oriented and cultivation of vocational ability of students based on service industry and economic development. Nowadays, traditional teaching quality evaluation system of higher vocational colleges cannot entirely satisfy educational particularity. Teaching quality evaluation indexes of higher vocational colleges can neither completely accord with students' vocational ability requirements in future work nor fully display development demand of vocational education and particularity of vocational education ${ }^{[1]}$.

\section{Basic principles of constructing teaching quality evaluation system of higher vocational colleges}

Through continuously studying and analyzing the defects and problems in specific implementation of teaching quality evaluation indexes of higher vocational colleges, this paper constructs and 
continuously improves teaching quality evaluation system of higher vocational colleges. During actually constructing teaching quality evaluation system of higher vocational colleges, the following basic principles should be met.

Firstly, organic combination of qualitative and quantitative evaluation. Qualitative evaluation and quantitative evaluation are actually two evaluation methods with different evaluation emphasis. Qualitative evaluation aims to analyze and observe things so as to discover the essence and key point of the things. Quantitative evaluation aims to rationally apply teaching method during statistics and data collection. During constructing teaching quality evaluation system of higher vocational colleges, colleges should organically combine qualitative evaluation and quantitative evaluation to improve scientificity of evaluation system and reach the purpose of enhancing evaluation accuracy.

Secondly, mutual unification of incentive and direction. Compared with common colleges, higher vocational colleges are employment-oriented. Hence, higher vocational colleges will take employment as the basic orientation during constructing teaching quality evaluation system, organically combine incentive means and teaching quality evaluation mechanism, guarantee to give full play to students' learning enthusiasm and teachers' teaching enthusiasm, and ensure effective improvement of students' employment ability so as to reach the purpose of overall improving teaching quality.

Thirdly, consistent operability and scientificity. When constructing teaching quality evaluation index mechanism, higher vocational colleges need to lay emphasis on scientific method and standards. In effect, scientificity actually refers to teaching quality evaluation mechanism which conforms to development and progress of higher vocational colleges. Besides, it is also necessary to ensure operable teaching quality evaluation mechanism. Based on guaranteeing to fully accords with teaching quality evaluation conditions of higher vocational colleges, teaching activity efficiency should be improved effectively.

Fourthly, dynamic nature. The teaching process of higher vocational colleges is a long-term implementation process, and the situation in a stage of teaching cannot entirely reflect actual teaching quality level of higher vocational colleges. To fully show practical teaching characteristics of higher vocational colleges, higher vocational colleges should own certain dynamic nature and rationally adjust index weight according to specialty development demand, student pool quality, innovative talent mode and market demand when constructing teaching quality evaluation system ${ }^{[2]}$.

\section{Construction of teaching quality evaluation system of higher vocational colleges}

In a bid to comply with actual demand of modern vocational education, higher vocational colleges need to rationally and practically construct teaching quality evaluation system in accordance with basic principles. Teaching quality evaluation indexes may be analyzed and studied from such aspects as employer, student and teacher.

\section{Teachers' teaching}

The fundamentality of education is the teacher. The teacher owns certain leading role in actual teaching process. After particularity of vocational ability training by higher vocational colleges is fully analyzed, vocational ability needs analyzing from the perspective of teaching. Teaching quality evaluation mechanism is constructed according to the following indexes.

\section{Vocational ability}

Vocational ability mainly involves exchange and cooperation ability, professional technical ability and teaching ability etc. For teachers, vocational ability basically contains talent training ability, basic vocational skills, education work, dual-ability, professional skills, industry-study-research combination, informatization accomplishment and social service etc.

Professional ethics

Professional ethics mainly examines teachers' moral cultivation, including teaching attitude, dedication and professional enthusiasm awareness, regulation and discipline observation, professional norm awareness and teaching relationship. Teacher's ethics actually refers to teachers' basic virtues, internal motivation, sense of mission, sense of responsibility and entrepreneur spirit. 
Favorable teachers' ethics can guarantee to promote students' establishment of good morality and personality and all-round development. It is very important in teaching quality evaluation of higher vocational colleges.

First-level indexes include vocational ability and professional ethics. The second-level indexes include vocational cultivation, teacher's ethics construction, professional technical ability, cooperation and exchange ability, teaching ability and other abilities. The third-level indexes involve professional norm, regulation and discipline observation, teaching relationship, vocational skills, dual-qualification quality, scientific research, university-enterprise cooperation, team building, practical teaching, classroom teaching, confidence, accomplishment and education etc.

\section{Students' learning}

The objects of education are students. In practical teaching, students own the dominant position. Whether students' learning can cultivate talents and meet the objective is an effective way to measure and test teaching quality of higher vocational colleges. According to the teaching evaluation, open and comprehensive teaching quality evaluation system with vocational ability training, classroom participation, innovation ability, independent study, informatization accomplishment, learning motivation, learning ability, learning attitude and professional ethics cultivation can be constructed. The evaluation system can integrate quality, ability and knowledge and improve students' innovation spirit and vocational ability to some degree. Basic evaluation objective of students' learning is to practically reflect and know innovation ability of teaching activity, comprehensive quality and learning quality etc. it owns great function in actual teaching process ${ }^{[3]}$.

The first-level indexes include vocational ability training and professional ethics cultivation. The second-level indexes include vocational cultivation, professional technical ability, quality level, learning ability and other abilities. The third-level indexes contain professional ethics, professional identity, learning motivation, learning attitude, honesty awareness, professional skills, professional knowledge, qualification certificate, independent study, teamwork, communication, learning method, learning practice, theory learning, post practice, innovation ability and foreign language ability etc.

\section{Employers' application}

In a sense, students belong to the products of education and need to be launched in the market in future, while the market is the employer. Product quality can embody teaching quality to some degree. Through evaluating employers' actual effect, colleges can test whether students' vocational ability training objective and talent training objective are reached, whether students' quality can be developed in an all-round way and whether the products meeting market development demand are owned. When students are employed, employers will evaluate them, which can properly reflect talent training quality of higher vocational colleges and plays certain role in constructing teaching quality evaluation system ${ }^{[4]}$.

The first-level indexes include vocational ability application and vocational manifestation. The second-level indexes include professional behavior, quality expansion, specialty application, working ability and other abilities. The third-level indexes contain enterprise culture identity, industry recognition, honesty, trustworthiness, dedication, professional skills, professional knowledge, qualification certificate, post adaptation, skill application, working efficiency, independent operation, foreign language ability, innovation ability and communication ability etc.

\section{Implementation of teaching quality evaluation indexes of higher vocational colleges}

In line with actual characteristics of higher vocational colleges (i.e. employment-based and market-oriented), students' education activity is evaluated according to teaching and learning in the teaching process, which can improve teaching quality and contributes to constructing teaching quality evaluation index mechanism with vocational ability and professional ethics. It is required to complete the component mechanism, demonstrate and examine the feasibility and scientificity of index mechanism. Besides, data statistics and questionnaire survey are adopted to investigate the weight, validity and reliability of indexes again, and then the specific weight and indexes are analyzed. Through continuous researches, the weight and indexes are implemented. Then, the teaching 
evaluation mechanism is revised again after the practice. Besides, external and internal indexes are verified to reach the purpose of teaching quality system of higher vocational colleges. The evaluation result should be fed back in time in teaching process so as to improve teaching quality and promote teaching reform ${ }^{[5]}$.

\section{Conclusion}

In conclusion, with social progress and development, teaching evaluation system of traditional higher vocational colleges cannot satisfy actual development demand gradually. This paper analyzes professional ethics and vocational ability from the employer, student and teacher according to practical development situation, and constructs teaching quality evaluation index mechanism which conforms to era demand. As well, continuous practice is organized to show actual conditions of teaching quality ands promote development of educational cause.

\section{Acknowledgement}

This paper belongs to "the 12th Five-year Plan" topic of Shandong vocational education and adult education research; title: Study on Construction and Application of Quality Evaluation System in Higher Vocational Education; topic No.: 2014zcj125

\section{References}

[1] He Zhijian, Luo Zihua, Liang Xukun et al., On Principles of Constructing Teaching Quality Evaluation System of Higher Vocational Colleges. Modern Enterprise Education, 2013(8):155-156.

[2] Lu Jianjun, Study on Teaching Quality Evaluation Indexes of Higher Vocational Colleges from Internationalization Perspective. Education and Vocation, 201,(6):28-30.

[3] Fan Mingcheng, Overview of Teaching Quality Influence Factors of Higher Vocational Colleges. Vocational and Technical Education, 2012,33(13):44-48.

[4] Guo Jingshi, New Path of Teaching Quality Evaluation System of Higher Vocational Colleges. Education and Vocation, 2012(2):28-29.

[5] Nie Yongcheng, Teaching Quality Management Framework of Higher Vocational Colleges under View of Stakeholders. Education Research Monthly, 2012(4):75-78. 